\title{
Aneuploidia: Marker of malignant colorectal adenomatous polyps
}

\author{
Marilena Stoian ${ }^{1,2 *}$, Lucia Indrei ${ }^{1}$ and Bogdan Stoian ${ }^{3}$ \\ ${ }^{1}$ Carol Davila University of Medicine and Pharmacy, Bucharest, Romania \\ ${ }^{2}$ Dr Ion Cantacuzino, Clinical Hospital, Bucharest, Romania \\ ${ }^{3}$ Medical Clinical Center, Polimed Apaca, Bucharest, Romania
}

\section{Introduction}

Due to the fact that colorectal cancer (CRC) usually develops from focal neoplastic lesions of adenomatous colorectal polyps, colorectal adenomas might be considered precancerous lesions and are resected endoscopically in order to prevent the progression to CRC by interrupting the adenoma-carcinoma sequence [1]. The histopathological features of adenomatous polyps classically regarded as risk factors for malignant transformation are associated with the size, grade of epithelial dysplasia and histological type [2]. One of the most important risk factors is the size of the polyp, as there is a $>40 \%$ chance for a larger than $2 \mathrm{~cm}$ adenomatous polyp to be malignant [3]. According to the WHO 25\% classification rule, colorectal adenomatous polyps are histologically classified as tubular, tubulo-villous and villous [4], the presence of extended villous features being associated with a greater risk of malignancy [3]. Dysplasia grading in adenoma is usually defined according to the revised Vienna classification of gastrointestinal epithelial neoplasia as either low-grade (epithelial neoplastic changes limited only to the epithelial glands) or high-grade (glandular irregularity and crowding with "back-to-back" glands, a cribriform architecture with prominent glandular budding) [5]. Highgrade dysplasia is usually associated with the development of CRC, but sometimes invasive carcinoma may stem from low-grade dysplasia.

It is currently accepted that DNA aneuploidy is associated with a poorer prognosis in CRC [6,7]. Furthermore, DNA aneuploidy proved that it could be a marker for the malignant transformation of several precancerous lesions (such as Barrett's esophagus [8], ulcerative colitis [9], giant melanocytic nevi [10] or cervical intraepithelial neoplasia [11]) in some papers studying the nuclear DNA content of the cells forming these lesions. These observations led to the hypothesis of a possible involvement of DNA ploidy in the process of malignant transformation of adenomatous colorectal polyps, hence a clinical use in predicting the development of CRC.

The aim of this study is to further investigate if DNA aneuploidy can serve as an early marker of malignant transformation of colorectal adenomatous polyps, by studying a group comprising 50 specimens of colorectal adenomas obtained via endoscopic resection. Flow cytometry was used to perform the analysis of the DNA content of the cells, the adenomatous and carcinomatous areas of the polyps being analyzed separately.

\section{Material and method}

The study was performed on 50 colorectal polyps obtained through endoscopic polypectomy from 46 patients, aged 30 to 80 , with a mean age of 60 . Our study included both completely benign tumors and polyps with focal neoplastic lesions.

All the patients included in the study gave their consent to be clinically and endoscopically examined, for the endoscopic resection of the polyps and to answer the questions from the study form. The study data was collected using individual study forms, and all 46 patients validated these forms by filling them out.

In order to assess the significance of DNA aneuploidy for the malignant transformation of colorectal adenomas, a distinct evaluation of nuclear DNA from the adenomatous and respectively from the focal malignant areas of the colorectal polyps was performed. Each polyp that was endoscopically resected was vertically split into two halves. $5 \mathrm{~mm}$ from the first half were sectioned and frozen at a temperature of $-70^{\circ}$, being immediately analyzed by flow cytometry. The remaining collected material was fixed with formaldehyde and embedded in paraffin for the histopathological examination of the specimens. From the frozen fragments, the histopathological examination identified benign adenomatous areas, which were sectioned apart from the malignant carcinomatous areas, in order to ensure a completely distinct analysis of the DNA nuclear material.

The pathological analysis revealed tubular, tubule-villous and villous polyps with diameters between 1 and $5 \mathrm{~cm}$, ranging from lowgrade to high-grade dysplasia.

\section{Flow cytometry analysis}

Specimen collection and processing was performed using a FACScan device (Becton-Dickinson) in the FACScan programme, while the WinMDI 2.8 programme was used for data analysis.

The FACScan programme allows not only the adjustement of the citometer and data acquisition, but also the sorting of cells. The results are presented as dot plot bidimensional graphics, in which each cell is represented as a dot depending on the intensity of the parameters marked on the axes of the graphic (FSC, SSC, FL-1 or FL-2). On such a graphic, obtained by reading the tube containing cells not marked with fluorocrome, where the cell are placed depending on their

${ }^{\star}$ Correspondence to: Marilena Stoian, MD, PhD., Assistant Professor, Matei Basarab Street, No 65, Bloc L109, Sc 2, Ap 27, District 3, P.O. 030675, Bucharest, Romania, Tel: +400733937310; Fax: 0214139917; E-mail: marilenastoian@ yahoo.com

Received: May 01, 2020; Accepted: May 08, 2020; Published: May 12, 2020 
size (expressed through the intensity of FSC) and their granularity (expressed through the intensity of SSC), a gate is established on the cells that are going to be investigated. On a dot plot defined by FL-1 ( $\mathrm{x}$ axis) and FL-2 (y axis) these cells will be grouped in a position corresponding to a minimum of fluorescence emitions.

After defining this logical gate the program will acquire only the data regarding the fluorescence (FL1 and FL2) resulting from the binding of marked antibodies with the target antigens. The information stemming from reading every tube is registered in the program memory and will be used in the data analysis process.

The graphic will be divided by two perpendicular lines into 4 quadrants, namely 1, 2, 3 and 4 from top left to bottom right, such as the negative control to be totally comprised by the quadrant no. 3. Quadrant no.1 will contain the cells that have bound the antibody marked with IP but not the one marked with ITCF (FL-1-/FL-2+), the quadrant no. 2 will contain those cells that have bound both antibodies (FL-1+/FL-2+), the quadrant no.3 will group the double negative cells (FL-1-/FL-2-), while the quadrant no.4 will contain FL-1+/FL-2- cells. The program will then automatically provide the percentage of events from each and every quadrant (Figure 1).

\section{Results}

Out of the 50 studied polyps, only 20 adenomas presented focal polypoid carcinomatous lesions. 69 histological specimens were analyzed using flow cytometry (50 pure adenomatous specimens and 19 specimens with carcinomatous transformation). Aneuploidy was present in 11 cases, while a single specimen presented with tetraploidy. The DNA index from histograms was 1.1 and the cellular aneuploidy percentage ranged from $5 \%$ to $79 \%$, with an average of $35 \%$ (Table 1).

In strictly adenomatous areas of studied polyps, diploidy was present in 43 cases (Figures 2 and 3), while aneuploidy only in 7 cases. 12 out of the 43 polyps with diploidy (i.e. $28 \%$ ) and all 7 polyps with aneuploidy also presented concomitant focal cancer lesions (Table 2).

Adenomas presenting with aneuploidy were associated with focal cancerous lesions in a greater proportion compared to those with diploidy $(\mathrm{P}<0.01)$.

The study of the cell cycle phases of the polyp fragments from the study group revealed not only diploid and aneuploid, but also hypodiploid cell populations (Figures 5-8).

In the neoplastic part of the 19 polyps with focal carcinomatous lesions, aneuploidy was present in 10 polyps (Table 1 - cases no. 1, 2, $3,4,5,6,8,9,10,11$ ) and in $60 \%$ of the cases ( 6 out of these 10 polyps) aneuploidy was also present in the adenomatous part (Table 1 - cases $1,2,3,4,5,6)$.

The DNA index (DI) in the adenomatous part was similar to the one of the carcinomatous part. In case no.7 aneuploidy was present in the adenomatous part of the polyp, while the carcinomatous did not exhibit aneuploidy, but diploidy (Figure 4).

In case no. 2 the polyp exhibited polyploidy in the adenomatous area, with a single aneuploid peak in the carcinomatous are (Figure 3).

The next step of a study was the analysis of aneuploidy and its relationship with carcinogenetic risk factors for colorectal polyps (Table 3) neuploidy was absent in all polyps smaller than $1 \mathrm{~cm}$, but it was registered in 4 out the 20 polyps between 1 and $2 \mathrm{~cm}$ diameter, as well as in 3 out the 8 polyps greater than $2 \mathrm{~cm}$. For these differences the value of $\mathrm{p}<0.05$ proves statistical significance.
Aneuploidy of the adenomatous areas tends to appear less frequently in low-grade dysplasia polyps (12\%) compared to highgrade dysplasia polyps (22\%), but without statistical significance.

There was no statistically significant correlation between DNA ploidy and the histologic type of adenomatous polyps.

\section{Discussion and conclusions}

In this study we highlighted the different frequency of aneuploidy between adenomas and carcinomas: aneuploidy is more frequent in polyp areas with carcinomatous transformation than in strictly adenomatous regions of the polyp. This difference might reflect the long natural history of the adenoma-carcinoma sequence, which takes place in several years.

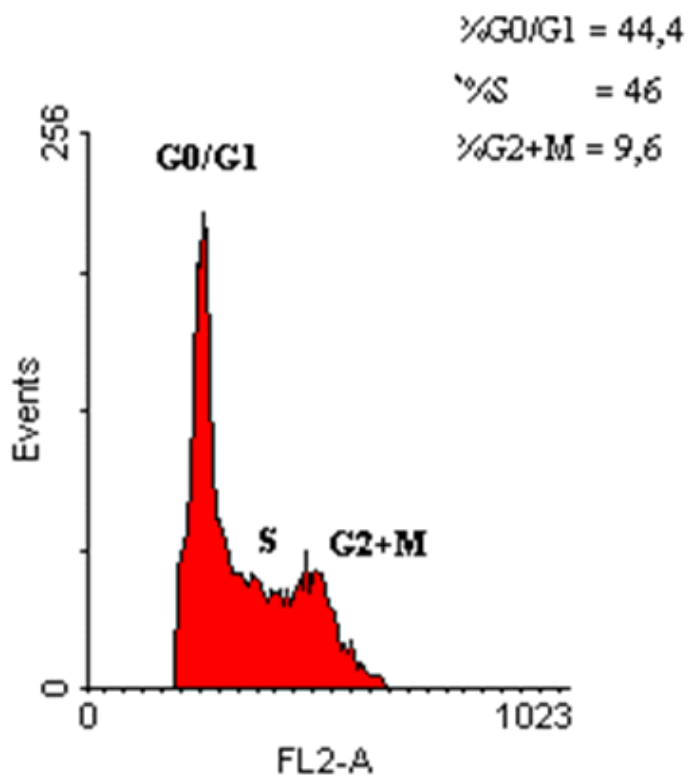

Figure 1. Assessment of the cell cycle phases of a polyp fragment from the study group using the RFIT program
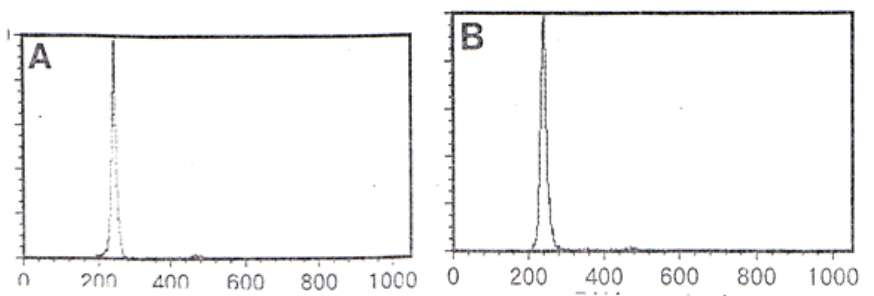

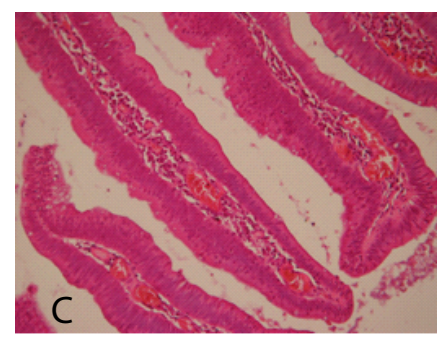

Villous adenomatous colonic polyp (40x, HE)

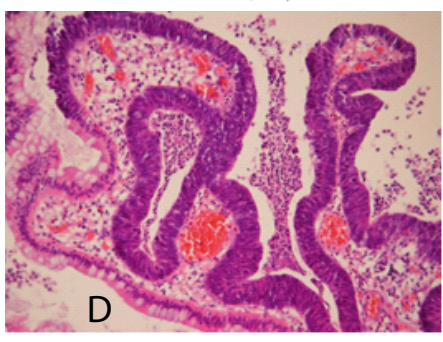

Villous adenomatous colonic polyp with malignant transformation and severe dysplasia areas $(200 \mathrm{x}, \mathrm{HE})$
Figure 2. Distribution of diploid cell populations (A, B) in adenomatous (C) and carcinomatous (D) polyp fragment 
The significant association between DNA aneuploidy and the size of the polyps is vital, as size is considered one of the most important predictors of carcinomatous transformation in an adenoma, followed in predictive ability by histopathological type and degree of dysplasia. The correlation between DNA aneuploidy and size proved in our study is similar to the conclusions of other studies [12-14]. Furthermore, the notable change in DNA ploidy of the adenomatous areas of the polyps in our study was notable when the size of the polyp became greater than $1 \mathrm{~cm}$ diameter (i.e. in polyps with a diameter between 1 and 2 $\mathrm{cm})$, congruent with a result of a previous study which describes the appearance of genetic alterations including K-ras mutations in polyps
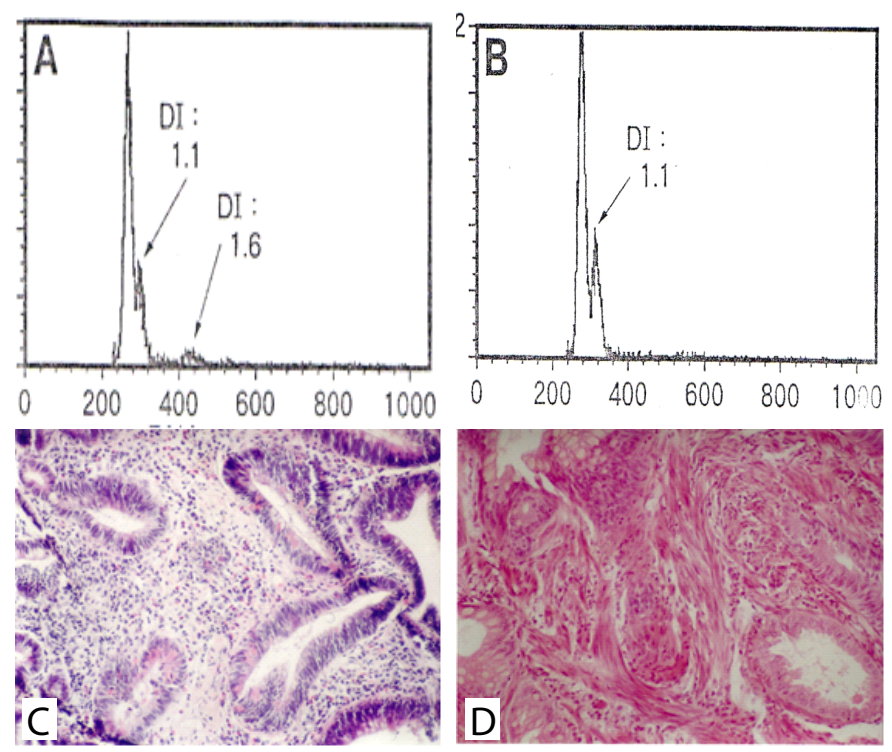

Sigmoid tubular adenomatous polyp, with with moderate epithelial dysplasia and Paneth cell metaplasia (200x, HE)

Detail: nests of atypical cells

infiltrating muscularis mucosae (400x, HE)

Figure 3. Distribution of aneuploid cell populations $(A, B)$ in adenomatous $(C)$ and carcinomatous (D) polyp fragment
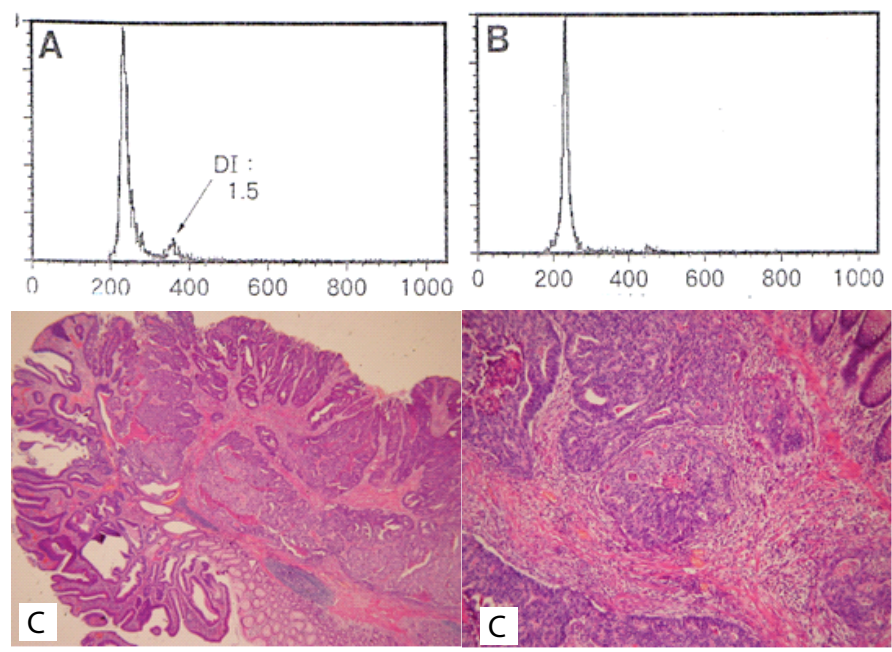

Tubulo-villous adenomatous polyp (100x, HE)

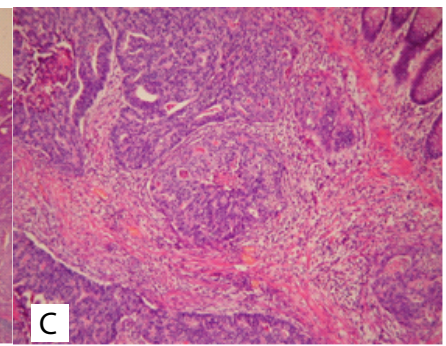

Mixed tubulo-villous adenomatous polyp with malignant transformation and areas of Invasion in muscularis mucosae $(100 \mathrm{x}, \mathrm{HE})$

Figure 4. Distribution of aneuploidy cell populations (A,B) in an adenomatous polyp fragment and of diploid cell populations (B) in a carcinomatous polyp fragment (D)

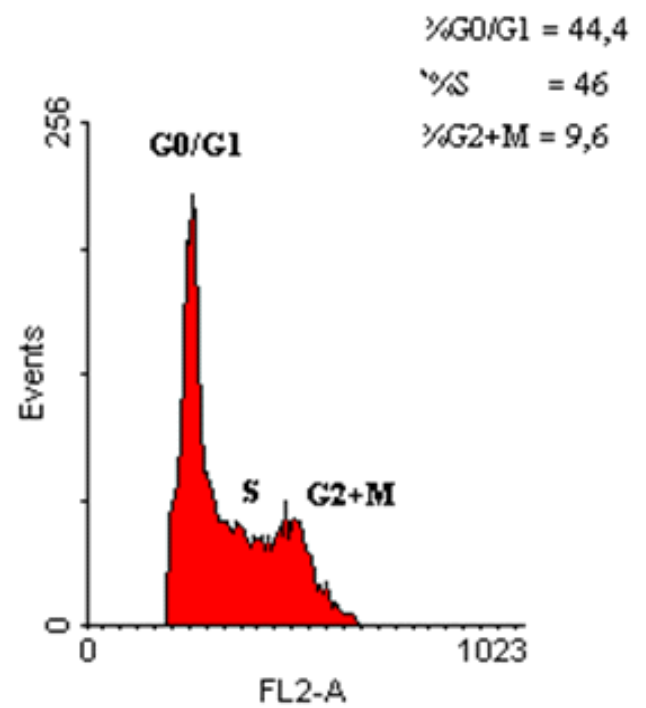

Figure 5. Assessment of cell cycle phases in a polyp fragment from the study group, using the RFIT program

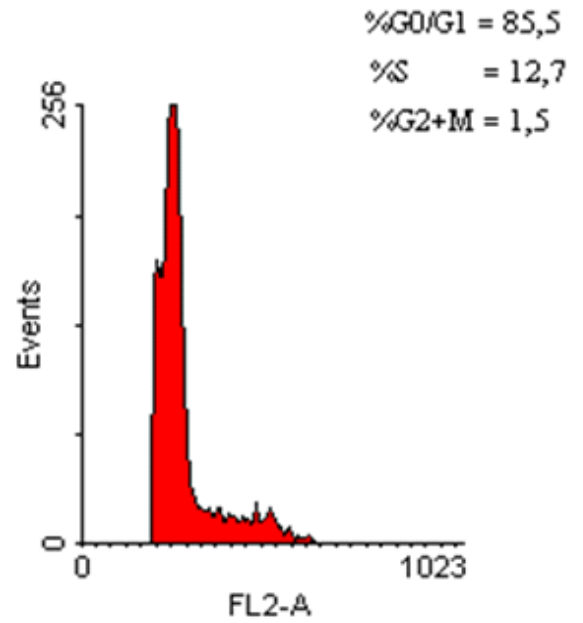

Figure 6. Distribution of hypoploid cell populations

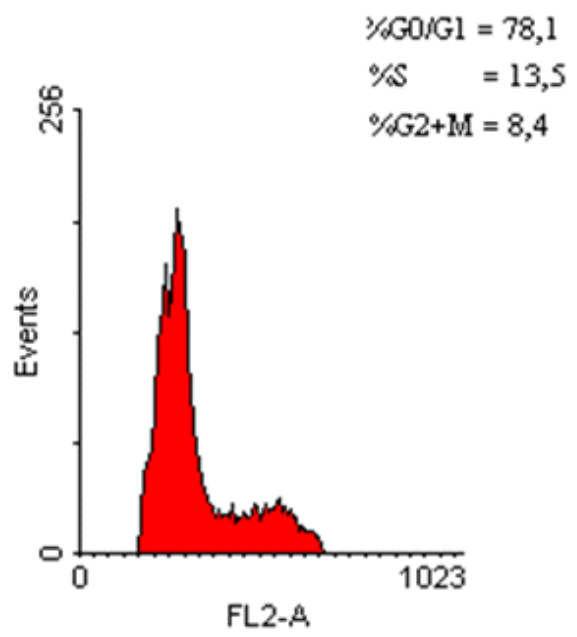

Figure 7. Distribution of hypodiploid cell populations in an adenomatous polyp fragment (70 - appearance of a small number of hypodiploid cells) 


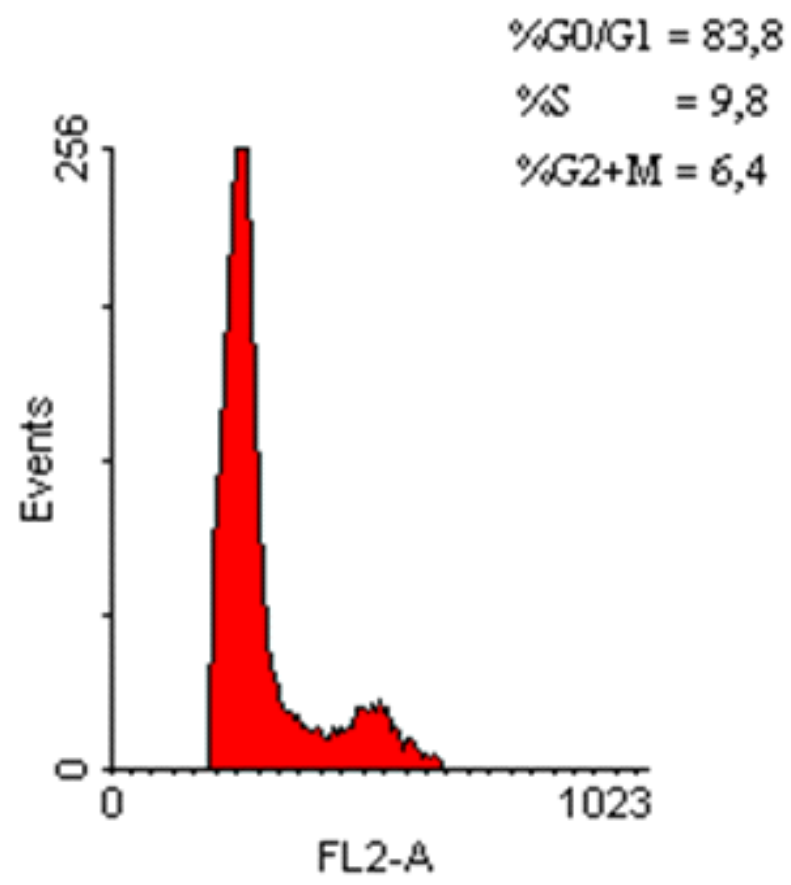

Figure 8. Distribution of hypodiploid cell populations in an adenomatous polyp fragment

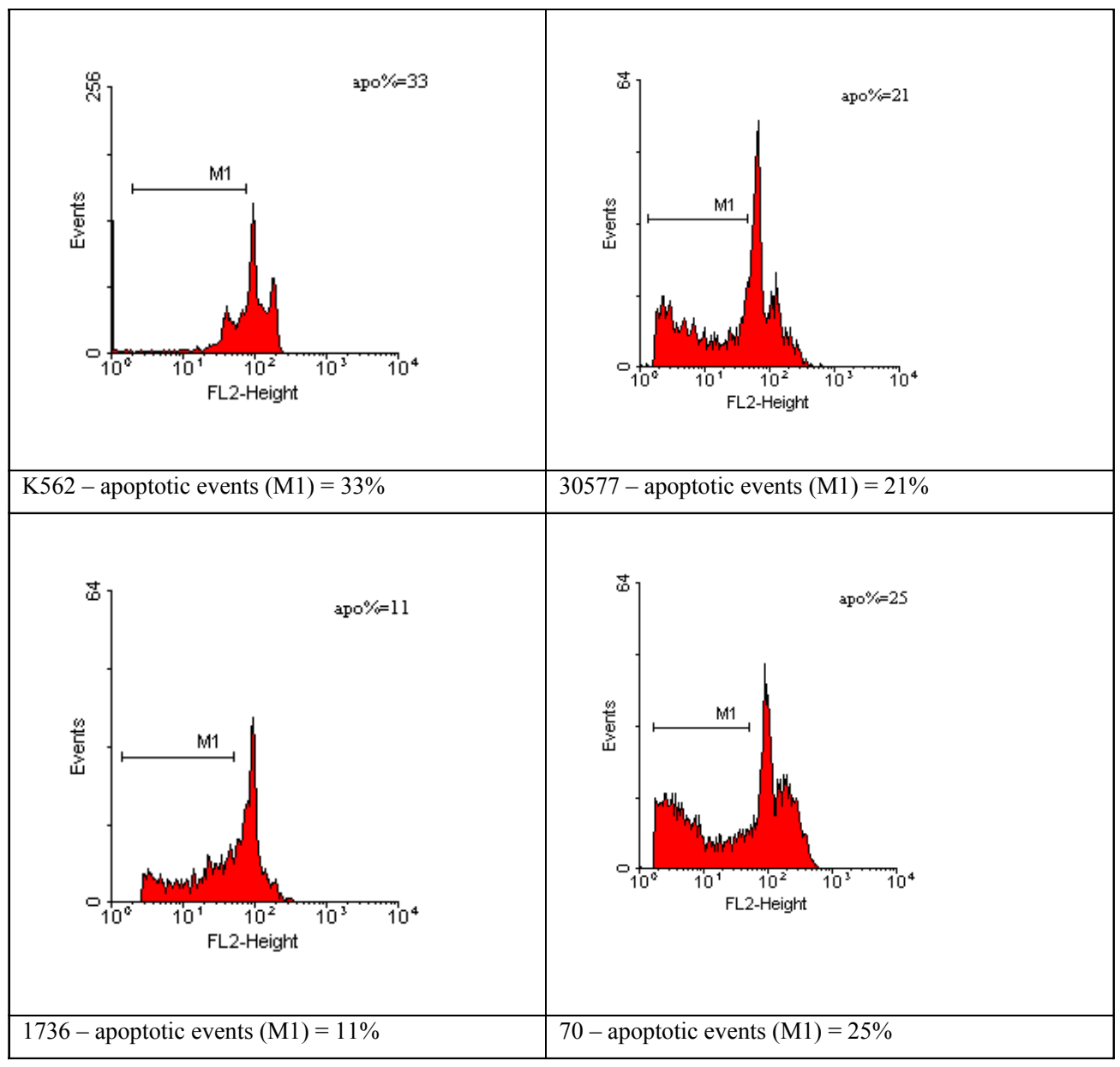

Figure 9. Distribution of apoptotic events in adenomatous polyp fragments from the study group 
Table 1. DNA index in adenomatous vs carcinomatous areas of colorectal polyps

\begin{tabular}{|c|c|c|c|c|}
\hline \multirow{2}{*}{ Current no. } & \multicolumn{4}{|c|}{ Polyp areas with DNA aneuploidy } \\
\cline { 2 - 5 } & Adenomatous area & \multicolumn{2}{c|}{ Carcinomatous area } \\
\cline { 2 - 5 } & DNA index & $\mathbf{\%}$ & DNA index & \% \\
\hline 1. & 1.1 & 56 & 1.1 & 37 \\
\hline 2. & 1.6 & 5 & 1.1 & 20 \\
\hline 3. & 1.4 & 46 & 1.2 & 52 \\
\hline 4. & 1.1 & 52 & 1.2 & 78 \\
\hline 5. & 1.7 & 58 & 1.7 & 79 \\
\hline 6. & 1.2 & 9 & 1.1 & 25 \\
\hline 7. & 1.5 & 13 & - & - \\
\hline 8. & - & - & 1.3 & 21 \\
\hline 9. & - & - & 1.1 & 37 \\
\hline 10. & - & - & 1.6 & 14 \\
\hline 11. & - & - & 1.3 & 18 \\
\hline 12. & - & - & 2.0 & 79 \\
\hline
\end{tabular}

Table 2. DNA ploidy in adenomas vs carcinomas $(\mathrm{P}<0.01)$

\begin{tabular}{|c|c|c|c|c|c|}
\hline \multirow{3}{*}{$\begin{array}{c}\text { Adenomas } \\
\text { Diploidy }\end{array}$} & \multicolumn{4}{|c|}{ Focal cancer } & \multirow{3}{*}{$\begin{array}{c}\text { Total } \\
43\end{array}$} \\
\hline & \multicolumn{2}{|c|}{ Absent } & \multicolumn{2}{|c|}{ Present } & \\
\hline & 31 & $72 \%$ & 12 & $28 \%$ & \\
\hline Aneuploidy & 0 & $0 \%$ & 7 & $100 \%$ & 7 \\
\hline
\end{tabular}

Table 3. DNA ploidy and carcinogenetic risk factors for colorectal polyps

\begin{tabular}{|c|c|c|c|c|}
\hline & & \multicolumn{3}{|c|}{ DNA ploidy } \\
\hline & & Diploidy & Aneuploidy & Total \\
\hline \multirow{3}{*}{ Polyp diameter } & $\mathrm{D}<1$ & 22 & 0 & 22 \\
\hline & $1<\mathrm{D}<2$ & 16 & 4 & 20 \\
\hline & $\mathrm{D}>2$ & 5 & 3 & 8 \\
\hline \multirow{2}{*}{ Dysplasia grade } & Low-grade & 36 & 5 & 41 \\
\hline & High-grade & 7 & 2 & 9 \\
\hline \multirow{2}{*}{ Histologic type } & Tubular & 22 & 5 & 27 \\
\hline & Tubulo-villous & 21 & 2 & 23 \\
\hline
\end{tabular}

with a diameter of 1-2 cm, together with the correlation between DNA aneuploidy and K-ras mutations $[15,16]$ or alterations of the $17 \mathrm{p}$ chromosome [17].

One interesting observation in our study refers to the DNA index in polyps with focal carcinomatous lesions, in which the carcinomatous areas have similar DNA indexes to those from the strictly adenomatous regions of the polyp. One can infer that DNA aneuploidy is already present in the adenomatous stage and that colorectal cancer cells stem from the aneuploid adenomatous cell clones, thus supporting the concept of the adenoma-carcinoma sequence. The case exhibiting polyploidy in the adenomatous area, with a single aneuploid peak in the carcinomatous area supports Nowell's model of clonal evolution in neoplasia [18], based on the assumption that during the carcinomatous transformation a neoplastic cell clone has been selected. According to Shackney, et al. the appearance of the aneuploid peak requires the activation of a gene responsible for the synthesis of a growth-factor [19], while Burner, et al. proved that in tumorigenesis the ploidy alterations are preceded by K-ras mutations [20]. To sum, the presence of aneuploidy in the strictly benign regions of the colorectal polyps reflects the genetic alterations occurring as early as the adenomatous stage of evolution.

While the association between DNA aneuploidy and the size of the adenomatous polyps was statistically significant $(\mathrm{p}<0.05)$, the study could not find any statistically significant correlation between DNA aneuploidy and the histopathological type or the severity of dysplasia, in contrast with the findings of Alcantara, et al. which proved a statistically significant association between aneuploidy and high-grade dysplasia adenomas $(\mathrm{p}<0.001)$, but no association between aneuploidy and the size of the adenomas [21].

The results of our study support the possible use of DNA aneuploidy as an early marker of carcinomatous transformation of colorectal adenomas, allowing the identification of more biologically aggressive tumors and thus selecting a group of patients in need of a more careful surveillance. However, some colorectal adenocarcinomas remain diploid over the entire course of their evolution, and in these cases the search for aneuploidy will not be able to identify all of the patients at risk of undergoing the adenoma-carcinoma sequence, underlining the need for the use of other predictor factors.

\section{References}

1. Simon K (2016) Colorectal cancer development and advances in screening. Clin Interv Aging 11: 967-976. [Crossref]

2. Salmo E, Haboubi N (2018) Adenoma and Malignant Colorectal Polyp: Pathological Considerations and Clinical Applications. EMJ Gastroenterol 7: 92-102.

3. Amersi F, Agustin M, Ko CY (2005) Colorectal cancer: Epidemiology, risk factors, and health services. Clin Colon Rectal Surg 18: 133-140.

4. Bosman FT (2014) WHO classification of tumours of the digestive system, Bosman FT, et al. (Eds), World Health Organization classification of tumours 2010, (4th Edn), Lyon: IARC Press.

5. Dixon MF (2002) Gastrointestinal epithelial neoplasia: Vienna revisited. Gut 51: 130131.

6. Araujo SE, Bernardo WM, Habr-Gama A, Kiss DR, Cecconello I (2007) DNA ploidy status and prognosis in colorectal cancer: a meta-analysis of published data. Dis Colon Rectum 50: 1800-1810. [Crossref]

7. Kouri M, Pyrhönen S, Mecklin JP, Järvinen H, Laasonen A, et al. (1990) The prognostic value of DNA-ploidy in colorectal carcinoma: a prospective study. Br J Cancer 62: 976-981.

8. Fennerty MB, Sampliner RE, Way D, Riddell R, Steinbronn K, et al. (1989) Discordance between flow cytometric abnormalities and dysplasia in Barrett's esophagus. Gastroenterology 97: 815-820.

9. Levine DS, Rabinovitch PS, Haggitt RC, Blount PL, Dean PJ, et al. (1991) Distribution of aneuploid cell populations in ulcerative colitis with dysplasia or cancer. Gastroenterology 101: 1198-1210. [Crossref]

10. Stenzinger W, Suter L, Schumann J (1984) DNA aneuploidy in congenital melanocytic nevi: suggestive evidence for premalignant changes. J invest Dermatol 82: 569-572.

11. Jakobsen A, Kristensen PB, Poulsen HK (1983) Flow cytometric classification of biopsy specimens from cervical intraepithelial neoplasia. Cytometry 4: 166-169.

12. Quirke P, Fozard JB, Dixon MF, Dyson JE, Giles GR, et al. (1986) DNA aneuploidy in colorectal adenomas. Br J Cancer 53: 477-481. [Crossref]

13. Giaretti W, Sciallero S, Bruno S, Geido E, Aste H, et al. (1988) DNA flow cytometry of endoscopically examined colorectal adenomas and adenocarcinomas. Cytometry 9: 238-244.

14. Perrin-Cottier M, Jouffre C, Sabido O, Maubon I, Barthelemy C, et al. (1991) Flow cytometric analysis of DNA content in colorectal polyps resected at endoscopy. Anal Quant Cytol Histo 13: 132-138.

15. Fearon ER, Vogelstein B (1990) A genetic model for colorectal tumorigenesis. Cell 61: 759-767. [Crossref]

16. Suchy B, Zietz C, Rabes HM (1992) K-ras point mutations in human colorectal carcinomas: relation to aneuploidy and metastasis. Int J Cancer 52: 30-33.

17. Offerhaus GJA, Feyter EPD, Cornelisse CJ, Tersmette KWF, Floyd J, et al. (1992) The relationship of DNA aneuploidy to molecular genetic alterations in colorectal carcinoma. Gastroenterology 102: 1612-1619.

18. Nowell PC (1976) The clonal evolution of tumor cell populations. Science 194: 23-28. [Crossref]

19. Shackney SE, Smith CA, Miller BW, Burholt DR, Murtha K, et al. (1989) Model for genetic evolution of human solid tumor. Cancer Res 49: 3344-3354. 
20. Burmer GC, Rabinovitch PS, Loeb LA (1989) Analysis of c-Ki-ras mutations in human colon carcinoma by cell sorting, polymerase chain reaction, and DNA sequencing. Cancer Res 49: 2141-2146.
21. Alcantara TM, Rodriguez MR, Repiso OA, de Lucas Veguillas A, Valle Munoz J, et al. (2005) DNA aneuploidy in colorectal adenomas. Role in the adenoma-carcinoma sequence. Rev Esp Enferm Dig 97: 7-15.

Copyright: (C2020 Stoian M. This is an open-access article distributed under the terms of the Creative Commons Attribution License, which permits unrestricted use, distribution, and reproduction in any medium, provided the original author and source are credited. 